Natural History in Brussels, are beginning to decay. The bones are unfortunately much pyritised, and being exposed to moist air, the pyrites becomes oxidised and causes disintegration. The director of the Museum, Dr. Victor Van Straelen, has for some time arranged to treat the more fragile parts with preservatives, but he realises that the only method of permanent preservation is to enclose the specimens in glass cases in which the air can be kept dry. $\mathrm{He}$ has accordingly induced the Belgian Government to ask Parliament for a sum of money sufficient to provide the cases. The Belgian Senate, however, after an animated discussion, has refused the appropriation on the ground that the preservation of these fossils is not worth the needed expenditure. To this Dr. Van Straelen has fittingly replied, that if the Belgian nation is unwilling to preserve so great a scientific treasure, the skeletons of Iguanodon should be offered for sale to museums in other countries, which would be glad to acquire them and keep them intact for research. Palæontologists everywhere will certainly endorse this proposition. The Belgian Senate, years ago, provided a large sum of money to obtain the unique collection of Iguanodons and other important fossils from the mine of Bernissart, to the great benefit of science and the enlightenment of the Belgian people. It is to be hoped that the Senate may yet reconsider its present retrograde step.

\section{Ultra-Short Wave Radio Links for Telephony}

IT is now well known that electric waves having a wave-length of less than about 8 metres are of little use for long-distance radio communication, owing to the apparent inability of the ionosphere to deflect such waves back to the earth's surface. For shorter distances and particularly over stretches of water, however, these short waves are being found to have a useful application in providing a radio link in the ordinary land-line telephone system. In this connexion, the radio link is an alternative to the use of a submarine cable, and it has the advantages of lower installation cost and ease of maintenance. An experimental two-way circuit of this type, operating on a wave-length of about five metres, was inaugurated by the Post Office engineers across the Bristol Channel in 1932 (see NaTuRE, 130, 604, Oct. 22, 1932). This radio circuit operates between Cardiff and Weston-super-Mare and links up with the ordinary inland telephone network, thus forming part of the London-Cardiff trunk circuit. The recent opening of a similar radio link, on a much shorter wave-length, across the English Channel for use in connexion with the cross-channel air services was referred to in NATURE of February 3, p. 167.

According to a report in the Times of February 24, the Postmaster-General, in his address to the Lincoln Chamber of Commerce, referred to the prob. able extension by the Post Office of the facilities provided in the radio link across the Bristiol Channel. Modern submarine cables usually contain many circuits so that several conversations are possible simultaneously; and a similar facility must be provided by the radio link if this is to compete success. fully with the cable. The experimental work which is now being conducted by the Post Office is directed towards ascertaining the practical possibilities of operating, between two fixed points, several small radio transmitters each on a separate wave-length and carrying a single conversation. The necessary equipment for this practical test is now being installed at Castleton, Monmouthshire, and at Backwell Hill, near Bristol. There will be six transmitters and six receivers on each site, and each of these will be associated with its own directional aerial system. All the twelve wave-lengths to be used will be within the range four to six metres. The whole system is being designed for economical operation, and such devices as the automatic charging of batteries and the indication at the controlling telephone exchange of faults on the radio link, are being incorporated. It is hoped to begin the tests in two or three months' time and the results of this larger-scale practical trial will be awaited with interest.

\section{Structure of Chlorophyll A}

THe fourth Pedler Lecture of the Chemical Society was delivered by Prof. Hans Fischer at the Royal Institution on February 22, his subject being the constitution of chlorophyll A. Prof. Fischer has been working on blood and leaf pigments in Munich for a number of years, and has recently synthesised hæmin, which is obtained from blood by heating with acetic acid and sodium chloride. $\mathrm{He}$ was awarded the Nobel prize for chemistry for 1930 . The lecturer dealt first with the porphyrins, a group of compounds upon which both hæmin and chlorophyll are based, and which all contain a ring of four pyrrole-like nuclei. Willstätter's work has shown that substances of this type are formed in the breaking down of chlorophyll, but now many of these complex molecules have been synthesised, and the nucleus of chlorophyll is known with certainty to be an isomeric modification of the porphyrin ring. The hæmin molecule has essentially the same nucleus, but different side chains. It contains two vinyl groups, which are hydrogenated to ethyl groups in chlorophyll. The latter also contains an additional ring structure, derived from $\beta$-keto propionic-acid, in place of the propionic acid side chain of the hæmin molecule. In chlorophyll, a magnesium atom re. places the co-ordinately bound iron atom of hæmoglobin. The final formulation of the structure of the chlorophyll molecule has entailed an enormous amount of synthetic organic chemistry of the utmost complexity. The brilliant manner in which Prof. Fischer and his co-workers have carried it out makes one confident that they will ultimately succeed in the synthesis of chlorophyll itself.

\section{Bootham School Natural History Society}

THE foundation of this School Natural History Society in 1834 was an important landmark in educational history, and a largely attended meeting at Bootham School, York, celebrated its centenary. An interesting exhibition of work done by past and present members gave striking evidence of the range 